\title{
Effect of Italy's motorcycle helmet law on traumatic brain injuries
}

\author{
F Servadei, C Begliomini, E Gardini, M Giustini, F Taggi, J Kraus
}

Injury Prevention 2003;9:257-260

\begin{abstract}
Objectives: To evaluate the impact of a revised Italian motorcycle-moped-scooter helmet law on crash brain injuries.

Design: A pre-post law evaluation of helmet use and traumatic brain injury (TBI) occurrence from 1999 to 2001 .

Setting: Romagna region, northeastern Italy, with a 2000 resident population of 983534 persons.

Participants: Motorcycle-moped rider survey for helmet use compliance and all residents in the region admitted to the Division of Neurosurgery of the Maurizio Bufalini Hospital in Cesena, Italy for TBI. Outcome measures: Helmet use compliance and change in TBI admissions and type(s) of brain lesions.

Results: Helmet use increased from an average of less than $20 \%$ to over $96 \%$. A comparison of TBI incidence in the Romagna region shows that there was no significant variation before and after introduction of the revised helmet law, except for TBI admissions for motorcycle-moped crashes where a $66 \%$ decrease was observed. In the same area TBI admissions by age group showed that motorcycle mopeds riders aged 14-60 years sustained significantly fewer TBls. The rate of TBI admissions to neurosurgery decreased by over $31 \%$ and epidural hematomas almost completely disappeared in crash injured moped riders.

Conclusions: The revised Italian mandatory helmet law, with police enforcement, is an effective measure for TBI prevention at all ages.
\end{abstract}

See end of article for authors' affiliations

Correspondence to: Dr Franco Servadei, WHO Neurotrauma

Collaborating Centre and Division of Neurosurgery, Ospedale "M Bufalini", 47023 Cesena, Italy; francoservadei@libero.it
T raumatic brain injury (TBI) is one of the most important causes of mortality and neuromotor, cognitive, and social disabilities in Italy and the world, and motorcycle crashes are one of the leading contributors to this problem. Reports from Asia, ${ }^{12}$ the South Pacific, ${ }^{34}$ Africa, ${ }^{56}$ Europe and Italy, ${ }^{7-9}$ and North America ${ }^{10}{ }^{11}$ show the immense impact of motorcycle crashes on neurotrauma and associated disability. Although many risk factors for crashes have been identified, such as alcohol use, ${ }^{12}$ driver fault, ${ }^{13}$ speeding, ${ }^{12}$ vehicle design, ${ }^{14}$ there has been little reported success in reducing motorcycle crash rates. The most successful injury prevention approach has been secondary-that is, reduction of the severity of injury after the crash and the secondary countermeasure most employed worldwide for this purpose has been motorcycle crash helmets.

Evidence on the effectiveness of motorcycle helmets to reduce head injuries in crashes comes from three different kinds of reports: (1) the comparison of the frequency, severity, and patterns of head injury in riders not using and using helmets, ${ }^{15} 16$ (2) pre-helmet and post-helmet law evaluation studies, ${ }^{9}{ }^{17-19}$ and (3) ecologic studies of regions or states with and without helmet laws. ${ }^{2021}$ All reports from all parts of the world come to the same general conclusion: helmet use laws with enforcement result in significant reductions in head injury frequency, and severity and deaths in motorcycle crashes. However, there is little evidence of the effect of helmet laws on the incidence of specific types of traumatic brain lesions.

A preventive countermeasure for TBI was introduced in Italy with the adoption of a national law (472/99) in March 2000. This law ratifies, as compulsory, the use of an approved helmet " . . for all motorbike, motorcycle and mopeds drivers, and their passengers, independent of their age". The law represents a dramatic change from an earlier July 1986 law, which required the use of helmets for all individuals only for motorcycles drivers whereas mopeds drivers had to wear a helmet only when less than 18 years of age. The premise of this earlier law was the belief that older riders had an adequate perception of the risks and benefits of wearing crash helmets. However, data from many epidemiological studies showed clearly that the largest proportion of deaths after motorcycle crashes involved individuals older than 18 years. ${ }^{3815} 18$ Italy had about 3500000 motorcycles and 7000000 mopeds in use in 2000. The new helmet law attempted to correct a national problem-that is, 385000 motorcycle crash injuries treated in accident and emergency departments, 75000 hospital admissions, and more than 1500 related deaths (mainly due to TBI without crash helmets) per year. ${ }^{22}$

The objective of this report was to evaluate the impact of Italy's compulsory helmet law on the change in helmet use and changes in frequency and specific types of motorcyclemoped crash TBI in the Romagna region of Italy. We chose to carry out this evaluation in this region because of the availability of helmet use data, the high compliance with the law, and detailed information on all serious TBI hospital admissions before and after the new law was implemented.

\section{METHODS}

\section{Helmet use}

The Italian National Health Institute, in anticipation of a revised helmet law, undertook an independent survey (Casco $2000^{23}$ ) to measure use of the motorcycle helmets in the country. As shown in previous studies, the introduction of a new helmet law does not necessarily guarantee their use. ${ }^{9}$ In the period February to June 2000, 57 local health care units (the administrative organisation of the Italian health care system), uniformly distributed over the national territory, monitored the use of helmets in their areas. This survey included about 300000 moped riders. About half of the units also provided data concerning emergency department visits due to moped crashes before and after the new law. 


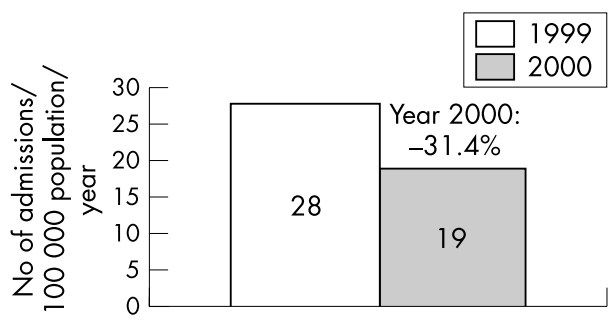

Figure 1 TBI hospitalization rates before and after the revised Italian motorcycle-moped helmet law.

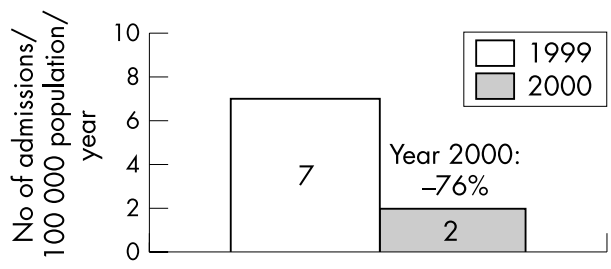

Figure 2 Incidence of neurosurgical hospital admissions for traumatic subarachnoid hemorrhage, subdural hematoma, and epidural hematoma due to motorcycle-moped crashes before and after the revised Italian motorcycle-moped helmet law.

Data from this survey showed a large increase in the correct use of the helmet (that is, correctly strapped under the jaw) in comparison with use patterns before the law..$^{23}$ In fact, helmet use was quite low in the period before introduction of the revised law, especially in the south and central areas of Italy. Helmet use after the law showed significant increase in the northern and central areas of Italy (90\%-95\%) compared with southern Italy (50\%-70\%). Also, data from the survey showed that the number of two wheeled motorized vehicles, in use throughout the country, did not decrease after the introduction of the new law.

\section{Motorcycles and mopeds in use}

Information on the number of registered mopeds was obtained from the "Associazione Nazionale Ciclo Motociclo Accessori" and data on circulating motorcycles was obtained from the "Automobile Club Italia".

\section{Helmet use in Romagna}

The Romagna region is located in the north east of Italy and has three districts: Ravenna, Rimini, and Forli'-Cesena; the total resident population in 2000 was 983 534. During the summer this number doubles because of the large number of tourists who are attracted to the many holiday resorts, pubs, and discos in the region.

Data for the Romagna region from the Casco 2000 survey showed that before the introduction of the revised helmet law (February to March 2000), the percentage of correct helmet use was only $19.5 \%$ in a stratified sample of 25356 motorcycle and moped drivers. ${ }^{23}$ In the period after enforcement of the revised law (April to June 2000), the percentage increased to $97.5 \%$ in a sample of 39327 motorcycle and moped drivers. This change was due to a public campaign in the media and to strong police enforcement.

\section{Traumatic brain injury data}

To evaluate the effects of the helmet law on TBI in Romagna, we examined the admission database of the Neurosurgery Division at the "Bufalini" Hospital, the only neurosurgical centre in the region. This hospital is equipped with computed tomography image transmission from all peripheral hospitals in the region. Guidelines for head injury management, coupled with computed tomography image transmission, ${ }^{24}$ resulted in the centralization of all brain injured patients requiring surgery or having the potential for an evolving intracranial lesions.

Furthermore, all comatose patients needing intracranial pressure monitoring are transferred to the Bufalini Hospital since the only neurointensive care unit is located in this hospital. Therefore, the TBI admission database of the Bufalini Hospital contains all of the most "severe" cases of TBI in all of Romagna. TBI patients from motorcycle crashes were identified electronically in this database.

Non-resident patients admitted for TBI were eliminated from the database. The incidence rate of motorcycle crash related TBI admission to the neurosurgery/neurointensive care unit (per $10^{5}$ population per year) was based on census data for the resident population.

For purposes of this study, 30 March 1999 to 29 March 2000 was designated as the pre-law year (1999), and 30 March 2000 to 29 March 2001 was the post-law year (2000).

\section{RESULTS}

As shown in fig 1 , the incidence rate per 100000 persons of TBI admissions to neurosurgery decreased significantly by $31.4 \%$ after introduction of the revised law. This reduction is highly significant $\left(\mathrm{p}<0.001, \chi^{2}=16.99\right)$. The change in rate was also seen using the number of registered motorcyclesmopeds in Romagna $(n=432000)$ as the unit of exposure. The rate pre-law was 63 per 100000 registered vehicles and the post-law rate was 43 per 100000 registered vehicles, a decrease of $31,7 \%\left(p<0.001, \chi^{2}=16.05\right)$

Specific TBI diagnoses also changed as a result of the helmet law (fig 2). For example, we observed a $76 \%$ decrease in the diagnosis of traumatic subarachnoid hemorrhage and subdural and epidural hematomas (International Classification of Diseases, 9th revision, clinical modification 852) due to motorcycle-moped crashes. This decrease was statistically significant $(\mathrm{p}<0.00001$, Fisher's exact test).

The changes in the neurosurgical/neurointensive care unit admissions were almost entirely due to a decrease in numbers of patients admitted with an epidural hematoma after moped crashes. For example, in 1998 there were 37 patients admitted with an epidural hematoma and in 1999 (the year before the new law), 42 patients were admitted. In the year after the introduction of the revised helmet law, only four patients were admitted with this TBI diagnosis. During the same period, the

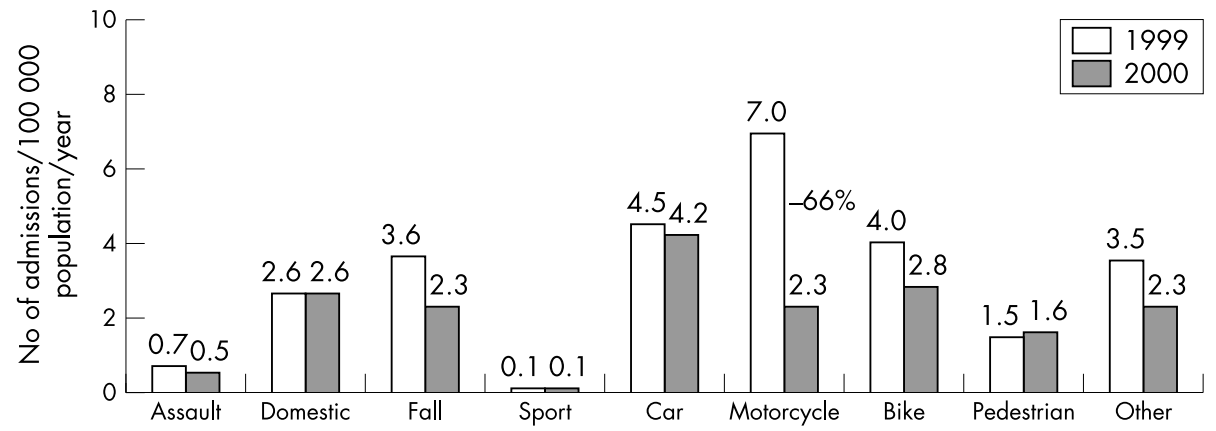

Figure 3 TBI hospital admissions by external cause before and after the revised Italian motorcycle-moped helmet law. 


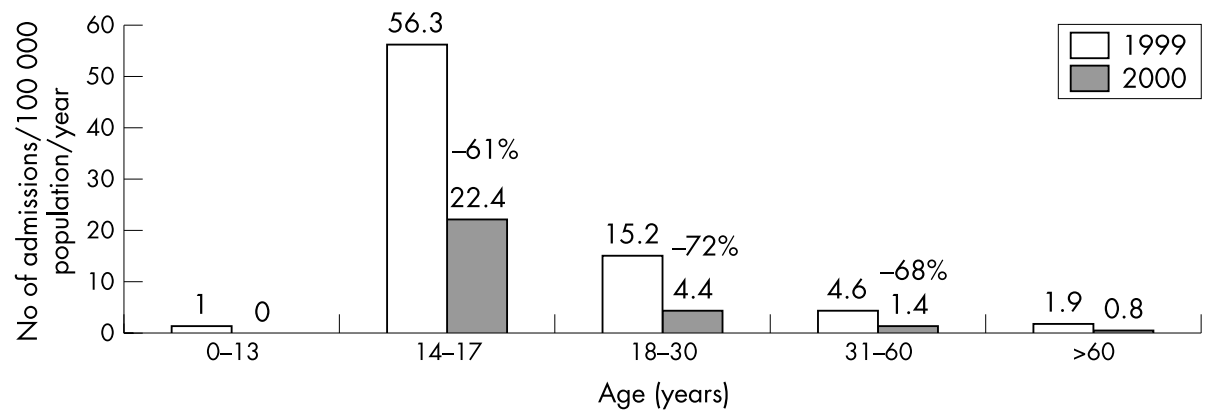

Figure 4 Age specific TBI hospital admission rates from motorcycle-moped crashes before and after the revised Italian motorcycle-moped helmet law. number of patients with acute subdural hematomas or diffuse
intracranial injuries decreased only slightly (17 patients in 1998, 18 patients in the year before the law, and 13 cases in the year after). These two hematoma series differed significantly $\left(\mathrm{p}<0.005, \chi^{2}=11.25\right)$

A comparison of all TBI incidence shows that there was no significant variation before and after introduction of the revised helmet law, with the exception of TBI admissions because of motorcycle-moped crashes (fig 3) where a 66\% decrease $\left(\mathrm{p}<0.0001, \chi^{2}=22.55\right)$ was observed.

TBI admissions by age group showed that motorcyclemoped riders aged $18-30$ years $\left(p<0.01, \chi^{2}=8.64\right), 31-60$ years $\left(p<0.05, \chi^{2}=5.88\right)$, sustain significantly less TBI (fig 4$)$. Patients aged $14-17$ years had also less TBI but had only marginal significance $\left(\mathrm{p}=0.052, \chi^{2}=3.78\right)$.

\section{DISCUSSION}

\section{Helmet use before and after the law}

In Italy, before 2000, the motorcycle helmet had not been accepted by motorcycle and especially by moped riders. Aesthetic, fatalistic, and climatic reasons were given for not using helmets. A survey conducted in 1986 before and after the introduction of the earlier law showed an increase in use of helmets (from 15\% to $96 \%$ ) for motorcycle drivers and (from $4 \%$ to 53\%) for moped drivers. ${ }^{9}$ In a recent study done in 1999 before the introduction of the new law, only $22.5 \%$ of injured scooter drivers wore a helmet in Rome. In Naples, only $3.4 \%$ of injured drivers wore helmets. ${ }^{22}$

Earlier data from Italy have demonstrated that helmet use reduces hospital admissions for head injuries by $28 \%-37 \% .{ }^{92}$ Similar results were also published for Taiwan. ${ }^{18}$ Our study confirms this effect by showing a 31\% decrease in admissions to the neurosurgical unit after the introduction of the new law (fig l).

Since new guidelines for head injury management and telemedicine image transfer were introduced at the same time as the revised helmet law, we studied in more detail the TBI population to try to separate the effects of helmet law from possible effects from these management changes.

The independent effect of helmet use in the decrease of TBI is highlighted by the fact that admissions for TBI from other external causes (fig 3) such as pedestrian, bicycle, or car crashes did not show any significant change after the national helmet law was introduced. Therefore, it is reasonable to conclude that the differences observed were not due to simultaneous changes in head injury management policy.

We also showed (fig 4) that the effect of helmet law enforcement is observed in almost all rider age groups. The decrease of head injury admissions among those $14-17$ years of age after the introduction of the new law shows that the earlier legislation was far from optimal. ${ }^{22}$ According to police, enforcement of a new law is much easier when all riders must wear a helmet.

\section{Specific reduction of intracranial hematomas}

Our findings are in agreement with that reported in a paper from Taiwan that demonstrated a significant decrease in

\section{Key points}

- Many studies in the US and Taiwan have shown the effectiveness of mandatory helmet use laws, but this is the first to show the impact of a mandatory law on traumatic brain injury (TBI) in a southern European country.

- The study demonstrates the effect of police enforcement of helmet use for all riders of two wheel motor vehicles, not just motorcycles.

- The study also demonstrates the importance of concurrent helmet use assessments at the time of TBI admissions to evaluate effectiveness.

- The positive impact of motorcycle helmet use on the most popular form of two wheeled motorized transportation in Italy (the moped or scooter) and other southern European countries is dramatically shown with the virtual disappearance of the common blunt impact head injury, the epidural hematoma.

intracranial post-traumatic hematomas after the introduction of a new helmet law. ${ }^{18}$ The data collected in this study show that the reduction of intracranial hematomas with the use of helmets in moped drivers is mainly due to the "disappearance" of one type of hematoma: the epidural hematoma. This hematoma is usually associated with the presence of a skull fracture and is considered the "typical" primary impact brain injury. The clinical pattern of this type of hematoma is the so-called "lucid interval", or a brief post-traumatic loss of consciousness followed by a period of normal consciousness and then followed by a comatose state. Since mortality associated with these hematomas can be zero ${ }^{25}$ when the diagnosis is made during the "lucid period" before the comatose state, heightened efforts have been dedicated to the management of apparently mild head injured patients with the aim of early diagnosis of intracranial hematomas.

We have shown that, in Italy with a large number of mopeds in use by younger riders, wearing helmets results in a significant decrease of epidural hematomas, whereas subdural or diffuse injuries, which generally occur from high speed impacts, are much less affected by helmet use. Confirmation of our findings in other regions of Europe with high use of mopeds or scooters is suggested.

\section{Study limitations}

Although national data on helmet use, before and after the new law, were available for all of Italy, detailed information on the impact of the law on TBI was limited to only the Romagna region of Italy. However, informal communications with neurosurgical colleagues (A Andreoli, A Barbanera, 2003) in Bologna (a city with the neurosurgical unit closest to the Romagna region) revealed a similar reduction in the incidence of epidural hematomas in the one year period after introduction of the revised helmet law. In addition, our colleagues report a $63 \%$ reduction in TBI hospital admissions because of motorcycle-moped crashes in their city. Nonetheless, an expanded study of the impact of the revised helmet law is 
needed to generalize the effect observed in the Romagna region to all of Italy.

\section{CONCLUSIONS}

We have observed that in the year 2000 in Romagna there was significant decrease in neurosurgical hospital admissions for motorcycle-moped TBI because of the adoption of the national compulsory helmet law. This dramatic decrease in TBIs after motorcycle-moped crashes was evident in all age groups. Epidural hematomas have almost disappeared in injured moped drivers after the introduction of the revised law.

It has been confirmed that the mandatory use of helmets, with police enforcement, is an effective measure for traumatic brain injury prevention at any age.

\section{Authors' affiliations}

F Servadei, C Begliomini, E Gardini, WHO Collaborating Centre on Neurotrauma, Maurizio Bufalini Hospital, Cesena, Italy

M Giustini, F Taggi, Italian National Health Institute, Rome, Italy J Kraus, WHO Collaborating Centre on Neurotrauma, UCLA Southern California Injury Prevention Research Center, Los Angeles, California, USA

\section{REFERENCES}

1 Sood S. Survey of factors influencing injury among riders involved in motorized two-wheeler accidents in India: a prospective study of 302 cases. J Trauma 1988;28:530-4.

2 Wang YC, P'eng F-K, Yang D-Y, et al. Epidemiological study of head injuries in central Taiwan. Chin Med J 1995:55:50-7.

3 Begg DJ, Langley JD, Reeder Al. Motorcycle crashes in New Zealand resulting in death and hospitalization: introduction methods and overview. Accid Anal Prev 1994;26:157-64.

4 Clarke JA, Langley JD. Disablement resulting from motorcycle crashes. Disabil Rehabil 1995; 17:377-85.

5 Dall G. The incidence of motorcycle accidents in South Africa-an alarming increase. S Afr Med J 1983;64:161-3.

6 Falope IA. Motorcycle accidents in Nigeria: a new group at risk. West Afr J Med 1991;10:187-9

7 Bjornsteg VL, Bylund PO, Lekander T, et al. Motorcycle fatalities in Sweden. Acta Chir Scand 1985;151:577-81.
8 Plasencia A, Borrell C, Anto JM. Emergency department and hospital admissions and deaths from traffic injuries in Barcelona, Spain: a one-year population-based study. Accid Anal Prev 1995;27:591-600. 9 Taggi F. Safety helmet law in Italy [letter]. Lancet 1988;i:182.

10 Sosin DM, Sacks JJ, Holmgren P. Head injury associated deaths from motorcycle crashes. JAMA 1990;264:2395-9.

11 Shankar BS, Ramzy Al, Soderstrom CA, et al. Helmet use patterns of injury, medical outcome, and costs among motorcycle drivers in Maryland. Accid Anal Prev 1992:24:385-96.

12 Holubowyzc OT, McLean AJ. Demographic characteristics, drinking patterns, and drunk-driving behavior of injured male drivers and motorcycle riders. J Studies Alcohol 1995;56:513-21.

13 Kraus JF, Anderson C, Zador $P$, et al. Motorcycle licensure, ownership and injury crash involvement. Am J Public Health 1991;81:172-6.

14 Kraus JF, Arzemanian S, Anderson C, et al. Motorcycle design and crash injuries in California, 1985. Bull N Y Acad Med 1988:64:788-803.

15 Romano PS, McLaughlin E. Helmet use and fatal motorcycle injuries in California, 1987-1988. J Head Trauma Rehabil 1991;6:21-37.

16 Rutledge R, Stutts J. The associations of helmet use with the outcome of motorcycle crash injury when controlling for crash severity. Accid Anal Prev 1993;25:347-51.

17 Kraus JF, Peek C, McArthur DL, et al. The effect of the 1992 California motorcycle helmet law on motorcycle crash fatalities and injuries. JAMA 1994; 272:1506-11

18 Chiu W-T, Kuo C-Y, Hung C-C, et al. The effect of the Taiwan motorcycle helmet use law on head injuries. Am J Public Health 2000;90:793-6.

19 Ferrand J, Plasencia A, Oros $M$, et al. Impact of a helmet law on two-wheel motor vehicle crash mortality in a southern European urban area. Inj Prev 2000;6:184-8.

20 Watson G, Zador PL, Wilks A. The repeal of helmet use laws and increased motorcyclist mortality in the United States, 1975-1978. Am J Public Health 1980;71:297-300.

21 Evans L, Frick MC. Helmet effectiveness in preventing motorcycle driver and passenger fatalities. Accid Anal Prev 1988;20:447-58.

22 La Torre G, Bertazzoni G, Zotta D, et al. Epidemiology of accident among users of two- wheeled motor vehicles: a surveillance study in two Italian cities. Eur J Public Health 2002;12:99-103.

23 Giustini M, Taggi F, and Gruppo. Casco 2000: the project "Casco 2000": further evidence of the efficacy of the law 472/99 [in Italian]. Proceedings of the 57th Conference on Traffic Injuries. Riva del Garda, 15-20 October 2001: 152-7.

24 Servadei F, Antonelli V, Mastrilli A, et al. Integration of image transmission into a protocol for head injury management. Br J Neurosurg 2002;16:36-42.

25 Bricolo A, Pasut LM. Extradural hematoma: toward 0 mortality. A prospective study. Neurosurgery 1984;14:8-12. 